\title{
Географические особенности формирования населения Оренбургской области
}

\author{
А.Н. Тюрин $ه$ \\ Оренбургский государственный педагогический университет, \\ Российская Федераиия \\ (460014, г. Оренбург, ул. Советская, 19)
}

\begin{abstract}
Аннотация: Цель: пространственный анализ динамики численности населения в Оренбургской области. Информационной базой исследования стали материалы Статистического управления по Оренбургской области, а также единая географическая база данных переписей населения. В ходе сравнительного анализа определены причины, влияющие на изменение демографической ситуации в регионе.

Результаты исследования: проанализированы и выявлены главные особенности и географические черты современной временной и пространственной динамики формирования населения Оренбуржья. Кроме того, составлены оригинальные графические материалы, среди которых половозрастная пирамида населения области на начало 2020 года, определены факторы, влияющие на депопуляцию, представлены основные демографические показатели и их количественная оценка.
\end{abstract}

Ключевые слова: Оренбургская область, депопуляция, демография, население, половозрастная пирамида, воспроизводство населения, этнический состав, трудовые ресурсы.

Для цитирования: Тюрин А.Н. Географические особенности формирования населения Оренбургской области // Вестник Воронежского государственного университета. Серия: География. Геоэкология, 2021, № 2, c. 44-48. DOI: https://doi.org/10.17308/geo.2021.2/3446

\section{ВВЕДЕНИЕ}

Н.Н. Баранский говорил, что не нужно «забывать человека» и изучение населения считал главным разделом и основой географического образования.

В настоящее время в Оренбургской области наблюдается естественная убыль населения. За 2019 год численность уменьшилась на 2000 человек, причем это связано как с падением рождаемости, так и с оттоком населения.

Если сравнивать численность населения области с начала XXI века, то она сократилась на $11 \%$. Данные изменения происходят в результате влияния воспроизводства населения, а также миграционных и этнокультурных процессов.

Лидером по численности населения является город Оренбург - 568773 человек, на 2 месте город Орск - 233235 человек и на 3 месте город Новотроицк 88216 человек.

За 18 лет численность Оренбургской области сократилась на 227896 человек, что сравнимо с населением такого города, как Орск. Именно поэтому изучение демографической ситуации имеет очень важное значения для дальнейшего существования региона.

\section{ОБСУЖДЕНИЕ РЕЗУЛЬТАТОВ}

С 1998 года, когда население области составляло 2,218 млн. человек (исторический максимум!), сегодня отмечается тенденция к ежегодному снижению его численности. На 1 января 2020 года численность населения Оренбургской области составила 1 млн. 963007 человек - это 24 место среди субъектов РФ, а плотность равна 15,87 чел./км² [1].

Показатели рождаемости и смертности в Оренбургской области с начала 2000 годов являются не стабильными, но можно отметить очевидное, что естественный прирост с 2013 года идет на убыль. На начало 2020 года естественная убыль населения равна $-0,7 \%$.

С 2005 по 2013 год показатели рождаемости росли не в связи с демографической политикой государства, направленной на повышение рожда-

(C) Тюрин А.Н., 2021

$\triangle$ Тюрин Александр Николаевич, e-mail: turin55@rambler.ru Контент доступен под лицензией Creative Commons Attribution 4.0 License. 
емости и стабилизацией численности населения, а с так называемыми «демографическими волнами». В этот период значительно снизился коэффициент младенческой смертности. Если в 2005 году он равнялся 13,0, то в 2015 году составил 6,8 . Начало депопуляции населения - 2016 год.

Одним из основных показателей качества жизни населения является ее средняя ожидаемая продолжительность. В Оренбургской области на 2019 год, согласно региональному Минздраву, она возросла с 70,57 до 70,94 лет (у мужчин - 65,5 лет, у женщин - 76 лет) [2].

По имеющимся данным нами была составлена половозрастная пирамида на 1 января 2020 года, по которой можно увидеть изменения населения в возрастном и половом составе (рисунок).

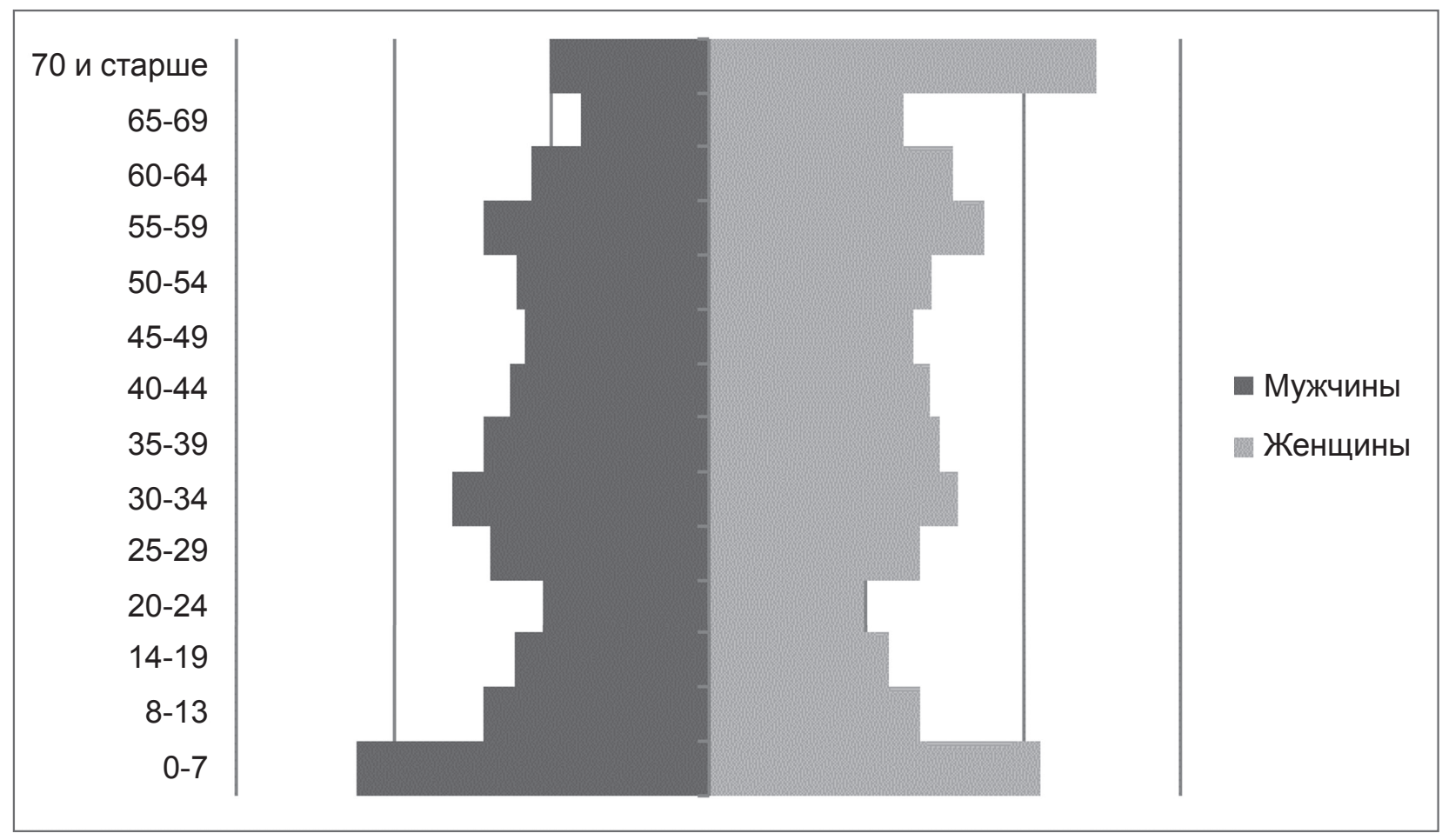

Puc. Половозрастная пирамида населения Оренбургской области (на 01.01.2020 г.) [составлено автором]

[Fig. Gender and age pyramid of the population in the Orenburg region (for the period of 01.01.2020) [compiled by the author]

Оказывается, что в разных возрастных группах изменения количества мужчин и женщин значительно отличаются. Самая малочисленная группа населения находится в возрасте от 20 до 24 лет, то есть это дети, родившиеся в «лихие» 90-е годы прошлого столетия. Данное время характеризуется социально-экономическим кризисом в стране, вызванным распадом СССР. Второй причиной такого падения уровня рождаемости стал переход к современному типу воспроизводства населения, когда для женщин на первое место стали выходить карьера и образование, а также желание иметь не более одного-двух детей в семье. К третьей причине низкой рождаемости можно отнести последствия Великой Отечественной войны, в годы которой рождалось небольшое количество детей, что также отражается на современной демографической ситуации как в Оренбургской области, так в России в целом [5].
Наибольшая численность в представленных возрастных группах приходится на период от 0 до 6 лет. Это связано с демографической политикой, проводимой в России, которая направлена на повышение уровня рождаемости в стране и «демографическими волнами». С 29 декабря 2006 года для поддержки молодых семей действует федеральная программа «Материнский капитал», благодаря которой уровень рождаемости, как в стране, так и в Оренбургской области значительно повысился. Так, если в 2006 году естественный прирост был равен $-4,0 \%$, то уже в 2007 году этот показатель составил -2,5\% \%. С 2012 по 2015 год наблюдается естественный прирост населения. Максимальный пока отмечен в 2013 году - 0,9\%

С уменьшением общей численности населения, но повышением продолжительности жизни меняется количество трудоспособного населения. 
Так, если в 2010 году численность населения трудоспособного возраста в области составляла $61,3 \%$, то на начало 2020 года она снизилась на 5,9\% и составила $55,4 \%$. В свою очередь доля лиц моложе трудоспособного возраста увеличилась с $17,4 \%$ до $20 \%$, а старше трудоспособного возраста с 21,3 \% в 2010 году до 24,6 \% в 2019.

Таким образом, происходит увеличение трудовой нагрузки на экономически активное население. В Оренбургской области на 1000 жителей трудоспособного возраста приходится 828 человек нетрудоспособного возраста, из них детей и подростков - 368 чел., лиц старше трудоспособного возраста - 460. Это заметно отличается от демографической нагрузки в среднем по России, где на 1000 жителей приходится только 757 лиц не трудоспособного возраста [3].

Население региона устойчиво продолжает уменьшаться за счет миграционной убыли: «минус» 3,5-4,5 человека на 1000 жителей. В область ежегодно приезжает из других субъектов РФ 17 тыс. человек, а покидают пределы области, уезжая в другие регионы России - 29 тысяч. Таким образом область каждый год теряет 8-10 тысяч человек [6].

Демографические процессы, происходящие в Оренбургской области в последние десятилетия, наряду со схожестью тенденций присущих для большинства субъектов РФ, имеют и отличительные для региона черты -показатели рождаемости и смертности.

Начиная с 1993 и по 2011 год, в области происходила депопуляция населения. Уровень рождаемости снизился на $37 \%$, а смертность увеличилась на $62 \%$ - смертность женщин выросла на $37 \%$, а мужчин увеличилась почти в 2 раза.

С середины 2000-х годов в области происходят обнадеживающие сдвиги в динамике демографических процессов - наблюдается повышение рождаемости и снижение смертности. За период 2000-2019 годов максимальное число родившихся приходилось на 2012 и 2013 годы. Уровень рождаемости в эти годы вырос до 14,8 \% года в области наблюдается вновь снижение числа рожденных детей. В 2018 году коэффициент рождаемости составлял 11,0 промилле.

Анализ демографических процессов показывает, что снижение естественной убыли и эпизодический прирост населения (2012-2015) не является постоянным. К 2017-2018 годам, когда репродуктивного возраста достигло поколение 90-х и начала 2000-х годов (рождаемость была самой низкой), объективно отмечается сокращение рож- даемости и новая волна демографического кризиса. Чтобы избежать втягивания в эту демографическую воронку, необходим запас демографической прочности - не менее 3-3,5 детей на одну семью. Однако улучшить демографическую ситуацию при помощи стимулов рождаемости крайне сложно. Так, за период 2005-2019 годов относительно высока динамика роста рождаемости $(38,1 \%)$, что превышает аналогичные показатели в среднем по России $(30,3 \%)$ и ПФО $(35,7 \%)$, но темпы снижения смертности за этот период незначительны (7,8 \%). Они существенно меньше, чем в среднем по Российской Федерации $(18,6 \%)$ и по ПФО $(15,2 \%)$.

Основные причины высокой смертности в Оренбургской области связаны с сердечно-сосудистыми и онкологическими заболеваниями. Очень высокая доля смертности (12-13\%), как по России, так и по области, от неестественных причин, особенно среди мужского населения: самоубийства $(80 \%)$, убийства (76\%), отравление алкоголем, передозировка наркотиками, гибель на производстве и в ДТП.

Исторически сложилось так, что в Оренбуржье доминирующими народами являются славянские, тюркские и финно-угорские. Заселение и хозяйственное освоение обширного края переселенцами из Центральной России и Поволжья, с одной стороны, соседство с районами традиционного проживания татар, башкир, казахов, чувашей, с другой, наложило своеобразный отпечаток на национальный состав населения области.

Например, в период освоения целинных земель в восточном Оренбуржье, где исторически сформировались районы расселения казахов, резко увеличилась доля славянского населения, прежде всего русского.

На 1 января 2020 года этнический состав Оренбургской области выглядел следующим образом: русские $-75,9 \%$, татары - 7,6 \%, казахи - 6,0 \%, украинцы - 2,5\%, башкиры - 2,3\%, мордва $1,9 \%$, немцы - $0,6 \%$, чуваши - $0,6 \%$, армяне $0,5 \%$, азербайджанцы - 0,4 \%, белорусы - 0,3\%, другие народы - $1,4 \%$.

Региональный рынок труда нельзя назвать сбалансированным. На протяжении последних 10-15 лет сохраняется «перепроизводство» юридических и экономических специальностей. Занятое в экономике Оренбуржья население имеет достаточно высокий уровень образования - высшее - 26,9 \%, а среднее - 52,7 \%, что сопоставимо с показателями в целом по России и Приволжскому федеральному округу. 
На рынке труда Оренбургской области происходят циклические колебания уровня безработицы, которая составляет 0,8-0,9 \%. Между тем, величина реальной (скрытой) безработицы существенно выше. По разным оценкам она составляет3-4 \% экономически активного населения. Высокий уровень общей безработицы в некоторых районах и городах (Медногорск, Новотроицк, Гай, Ясный).

\section{ЗАКЛЮЧЕНИЕ}

В результате длительного процесса исторического освоения и заселения Оренбургской области сформировалась современная демографическая картина.

В древности через территорию Оренбуржья проходили с востока на запад волны народов кочевников, которые оставили здесь свой культурный след. Заселение территории современной Оренбургской области русскими началось в конце XVII века. Рост численности населения осуществлялся главным образом в центральной и восточной частях Оренбуржья, где происходило интенсивное промышленное освоение [4].

В ходе проведённого исследования установлено, что средняя ожидаемая продолжительность жизни в Оренбургской области с 2005 года существенно выросла, но, как и в других районах России, этот уровень является низким по сравнению с экономически развитыми странами мира.

Как в России в целом, так и в нашем регионе, в возрастном составе населения заметны отличия по количеству представителей мужского и женского пола. Так, если в младших возрастных группах наблюдается значительный перевес в мужскую сторону, то уже после 30-35 лет, вследствие более высокой смертности среди мужчин, количество женщин увеличивается.

И всё-таки, главной причиной динамики численности населения являются так называемые «демографические волны», начало которых, в первую очередь, можно отнести к периоду Великой Отечественной войны. В настоящее время в репродуктивный возраст вступили правнуки участников военных действий того времени, а так как на тот момент наблюдалась естественная убыль, то и сейчас населения не хватает, для того чтобы поддерживать естественный прирост.

\section{СПИСОК ЛИТЕРАТУРЫ}

1. Герасименко Т.И. Филимонова И. Ю. Этнокультурная география Оренбургской области. Оренбург: ГОУ ОГУ, 2009. $92 \mathrm{c}$.

2. Семенов Е.А. Герасименко Т.И., Ахметов Р.Ш. Современная геодемографическая ситуация в Оренбургской области // Материаль II Всероссийской научно-практической конференции «Инновачионные проиессы в области химико-педагогического и естественнонаучного образования», 2012, с. 250-255.

3. Тюрин А.Н. Современная демографическая ситуация в Оренбургской области // Географические исследования Сибири и сопредельных территорий, 2019, c. 81-83.

4. Ахметов Р.Ш., Филимонова И.Ю., Ахметова Н.И. Динамика расселения населения в зоне Российско-Казахстанского приграничья // Вестник Воронежского государственного университета. Серия: География. Геоэкология, 2020, №2, с. 29-34. DOI: https://doi. org/10.17308/geo.2020.2/2882.

5. Соколов А.А. Территориальный анализ размещения и сдвигов населения в степной зоне России // Becmник Воронежского государственного университета. Серия: География. Геоэкология, 2016, №1, с. 24-29.

6. Чибилёв А.А. (мл.), Семёнов Е.А. Григоревский Д.В. Проблемы и специфика сельского расселения в Оренбургской области // Вестник Воронежского государственного университета. Серия: География. Геоэкология, 2016, №1, с. 34-38.

Конфликт интересов: Автор декларирует отсутствие явных и потенциальных конфликтов интересов, связанных с публикацией настоящей статьи.

Поступила в редакичию 03.09.2020 Принята к публикации: 28.05.2021 


\title{
Geographical Features of Population Formation in the Orenburg Region
}

\author{
A. N. Tyurin $\bowtie$ \\ Orenburg State Pedagogical University, Russian Federation \\ (19, Sovetskaya St., Orenburg, 460014)
}

\begin{abstract}
The purpose is spatial analysis of population dynamics in the Orenburg Region. The informational background of the research work includes the data of the Statistical office of the Orenburg Region, as well as the unified geographical database of population censuses in the Orenburg Region. In the course of the comparative analysis, the reasons that affect the change in the demographic situation in the region are identified.

Research results: the main features and geographical features of modern time and spatial dynamics of the Orenburg Region population formation are analyzed and identified. In addition, the original graphic materials were compiled, including the gender and age pyramid of the region's population at the beginning of 2020, the factors causing depopulation in the Orenburg Region were identified, too. The main demographic indicators and their quantitative assessment were presented.

Key words: Orenburg Region, depopulation, demography, population, gender and age pyramid, population reproduction, ethnic composition, manpower.

For citation: Tyurin A.N. Geographical Features of Population Formation in the Orenburg Region. Vestnik Voronezskogo gosudarstvennogo universiteta. Seria: Geografia. Geoekologia, 2021, no. 2, pp. 44-48. (In Russ.) DOI: https://doi.org/10.17308/geo.2021.2/3446
\end{abstract}

\section{REFERENCES}

1. Gerasimenko T. I. Filimonova I. Yu. Etnokul'turnaya geografiya Orenburgskoy oblasti [Ethnocultural Geography of the Orenburg region]. Orenburg: GOU OGU, 2009. 92 p. (In Russ.)

2. Semenov E.A. Gerasimenko T.I., Akhmetov R. Sh. Sovremennaya geodemograficheskaya situatsiya v Orenburgskoy oblasti [Modern geodemographic situation in the Orenburg region]. Materialy II Vserossiyskoy nauchno-prakticheskoy konferentsii "Innovatsionnye protsessy $v$ oblasti khimiko-pedagogicheskogo i estestvennonauchnogo obrazovaniya», 2012, pp. 250-255. (In Russ.)

3. Tyurin A.N. Sovremennaya demograficheskaya situatsiya v Orenburgskoy oblasti [Modern demographic situation in the Orenburg region]. Geograficheskie issledovaniya Sibiri i sopredel'nykh territoriy, 2019, pp. 81-83. (In Russ.)

4. Akhmetov R. Sh., Filimonova I. Yu., Akhmetova N.I. Dinamika rasseleniya naseleniya $\mathrm{v}$ zone Rossiysko-Kazakhstanskogo prigranich'ya [Dynamics of population settlement in the zone of the Russian-Kazakhstan border].

Тюрин Александр Николаевич

кандидат географических наук, доцент кафедры географии и методики преподавания географических дисциплин Оренбургского государственного педагогического университета, г. Оренбург, Российская Федерация, ORCID: 0000-0002-4079-3610, e-mail: turin55@ rambler.ru
Vestnik Voronezhskogo gosudarstvennogo universiteta. Seria: Geografia. Geoekologia, 2020, no. 2, pp. 29-34. DOI: https://doi.org/10.17308/geo.2020.2/2882. (In Russ.)

5. Sokolov A.A. Territorial'nyy analiz razmeshcheniya i sdvigov naseleniya v stepnoy zone Rossii [Territorial analysis of the placement and shifts of the population in the steppe zone of Russia]. Vestnik Voronezhskogo gosudarstvennogo universiteta. Seria: Geografia. Geoekologia, 2016, no. 1, pp. 24-29. (In Russ.)

6. Chibilev A.A. (ml.), Semenov E.A. Grigorevskiy D. V. Problemy i spetsifika sel'skogo rasseleniya v Orenburgskoy oblasti [Problems and specifics of rural settlement in the Orenburg region]. Vestnik Voronezhskogo gosudarstvennogo universiteta. Seria: Geografia. Geoekologia, 2016, no. 1, pp. 34-38. (In Russ.)

Conflict of interests: The author declares no information of obvious and potential conflicts of interest related to the publication of this article.

Received: 03.09.2020 Accepted: 28.05.2021

Alexander N. Tyurin

Cand. Sci. (Geogr.), Associate Professor of the Department of Geography and Methods of Teaching Geographical Disciplines, Orenburg State Pedagogical University, Orenburg, Russian Federation, ORCID: 0000-0002-4079-3610, e-mail: turin55@rambler.ru

(C) Tyurin A. N., 2021

$\triangle$ Alexander N. Tyurin, e-mail: turin55@rambler.ru The content is available under Creative Commons Attribution 4.0 License. 